DOI: $10.14746 /$ por.2019.1.20

\title{
OGRANICZENIA DEMOKRATYCZNEJ KONSOLIDACJI. PODWAŻANIE ROZUMU JAKO SYNDROM POSTTOTALITARNY
}

\author{
Dragoș Petrescu ${ }^{1}$ \\ (Universitatea din București)
}

\begin{abstract}
Słowa kluczowe: ideologia, instytucje, społeczeństwo obywatelskie, kultura, powrót dysydentów, The Legacies of Totalitarianism, Aviezer Tucker

Keywords: ideology, institutions, civil society, culture, return of dissidents, The Legacies of Totalitarianism, Aviezer Tucker
\end{abstract}

\begin{abstract}
Abstrakt: Dragoş Petrescu, OGRANICZENIA DEMOKRATYCZNEJ KONSOLIDACJI. PODWAŻANIE ROZUMU JAKO SYNDROM POSTTOTALITARNY. „PORÓWNANIA” 1 (24), 2019. T. XXIV, S. 251-255. ISSN 1733-165X. Mój komentarz do książki Aviezera Tuckera dotyczy czterech kwestii, które Francis Fukuyama definiuje jako cztery poziomy, na których musi zachodzić konsolidacja demokracji: 1. Ideologia, 2. Instytucje, 3. Społeczeństwo obywatelskie i 4. Kultura. Książka Tuckera dostarcza wnikliwej analizy roli odgrywanej przez każdą z tych sfer w postkomunistycznym społeczeństwie. Badając wnikliwie dziedzictwo totalitaryzmu, Tucker dochodzi do wniosku, że totalitaryzm nie jest martwy i częściowo przynajmniej powraca. Aby się przed nim obronić, proponuje on proste rozwiązanie: powrót dysydentów. Nowi neo-dysydenci mogą zbawić swoje posttotalitarne społeczeństwa od nienawiści, kłamstw i płytkiego pragmatyzmu poprzez miłość, prawdę i osobistą integralność. Musimy niestety nieco poczekać, aby przekonać się, czy propozycja Tuckera jest skuteczna.
\end{abstract}

\begin{abstract}
Dragoş Petrescu, LIMITS OF DEMOCRATIC CONSOLIDATION. UNDERMINING REASON AS A POST-TOTALITARIAN SYNDROME. "PORÓWNANIA" 1 (24), 2019. Vol. XXIV, P. 251-255. ISSN 1733-165X. My intervention on Aviezer Tucker's book addresses four key issues, which Francis Fukuyama defines as the four levels on which consolidation of democracy must take place: (1) ideology; (2) institutions; (3) civil society; and (4) culture. Tucker's analysis provides insightful reflexions on the role played by each of these four spheres in the post-totalitarian setting. By thoroughly examining totalitarian legacies, Tucker concludes that totalitarianism is
\end{abstract}

1 E-mail: dragos.petrescu@fspub.unibuc.ro 
not dead and has already made a partial return. To resist and even reverse this phenomenon, he sets forth a disarmingly simple solution: the return of dissidents. Neo-dissidents might save their post-totalitarian societies from hate, lies and sheer pragmatism through love, truth and personal integrity. Only time will tell if Tucker's solution works.

W cudownym roku 1989 w sześciu państwach Europy Środkowej i Wschodniej upadły dyktatury komunistyczne i rozpoczęła się nowa epoka europejskiej i światowej historii. Po niespodziewanym upadku Związku Radzieckiego i krwawym rozpadzie Jugosławii wydawało się, że nic nie zakłóci globalnej ekspansji demokracji. Gdy latem 1989 roku Francis Fukuyama ogłosił, że zbliża się koniec historii oraz triumf liberalnej demokracji i wolnorynkowej gospodarki, zyskał niemal z dnia na dzień sławę i rozgłos. Tymczasem minęły zaledwie dwie dekady po wspomnianych zmianach ustrojowych, a wielkie nadzieje na "koniec historii” i „powrót do Europy" zdążyły się stopniowo przemienić w gorzkie rozczarowanie. Pojawiły się napomknienia o "powrocie historii", a potem - w związku z Brexitem - także o "pożegnaniu z Europą".

Jak podkreślali uczestnicy dyskusji nad książką The Legacies of Totalitarianism, jej autor, Aviezer Tucker, badając problem "dziedzictwa totalitaryzmu”, w rzeczywistości omawia różnorodne aspekty demokratycznej transformacji oraz niepokojące oznaki przekształceń wiodących w przeciwnym kierunku w Europie Środkowo-Wschodniej. Moim zamierzeniem jest odnieść się do tych prowokujących, a czasem wręcz ikonoklastycznych stwierdzeń autora, ze szczególnym uwzględnieniem zjawiska, które nazywam zbliżającym się przejściem od demokratyzacji do autokratyzacji $\mathrm{w}$ omawianym regionie, mając na uwadze, że pozostali komentatorzy skupiać się będą na innych, równie istotnych i aktualnych kwestiach poruszanych w tej dającej dużo do przemyśleń książce.

Od samego początku należy zaznaczyć, że Tucker postrzega „dziedzictwa totalitaryzmu" i - można by dodać - deficyty demokracji w regionie jako objaw charakterystyczny dla wszystkich państw postkomunistycznych. W ten sposób autor zamiast przyjrzeć się różnicom pomiędzy poszczególnymi krajami, koncentruje się - z powodzeniem - na zbudowaniu silnej argumentacji na rzecz wspólnego dziedzictwa totalitaryzmu. Inną strategię zastosowano we wcześniejszych analizach procesów demokratyzacji w postkomunistycznej Europie. Na przykład Attila Ágh w wydanej w 1998 roku książce The Politics of Central Europe wprowadza wyraźne rozróżnienie pomiędzy regionem, który nazywa Europą Środkowo-Wschodnią (Chorwacja, Czechy, Węgry, Polska, Słowacja i Słowenia) a Bałkanami (Albania, Bośnia i Hercegowina, Bułgaria, Macedonia, Rumunia i Serbia). Odnosząc się do tej pierwszej grupy państw, Ágh używa terminu redemokratyzacja, a do drugiego demokratyzacja (Ágh 1998: 7; 1999: 269-270). W związku z tym rodzi się jednak pytanie, dlaczego przebiegające obecnie procesy reautokratyzacji rozpoczęły się, jak się zdaje, w państwach, które w latach dziewięćdziesiątych XX wieku doświadczy- 
ły, pace Ágh, redemokratyzacji, a nie demokratyzacji. Jak już zostało wspomniane, Tucker unika takiej pułapki, koncentrując się bardziej na wspólnych aspektach komunistyczno-totalitarnego dziedzictwa niż na rozbieżnościach.

Jeśli chodzi o liczne inspirujące zagadnienia prezentowane przez Tuckera w omawianej publikacji, zanalizuję cztery kluczowe kwestie zdefiniowanych przez Fukuyamę jako cztery poziomy, na których odbywać się ma konsolidacja demokracji. Są to: (1) ideologia, (2) instytucje; (3) społeczeństwo obywatelskie oraz (4) kultura (Fukuyama 320-321). W mojej opinii analizy Tuckera obejmują każdy z tych poziomów. Z tego względu poniżej omówię pokrótce - aczkolwiek w innej kolejności - rozważania Tuckera na temat roli odgrywanej przez każdą ze wspomnianych czterech sfer, a na koniec odniosę się do dość zaskakującego rozwiązania tego trudnego problemu, które zaproponował. Swój komentarz zilustruję czterema fragmentami omawianej książki dotyczącymi poszczególnych sfer.

Pierwszy cytat dotyczy ideologii:

Wszechobecne, niebezpieczne i rzadko dostrzegane dziedzictwa ideologii totalitarnych nie kryją się $\mathrm{w}$ politycznych utopiach i programach ani nawet $\mathrm{w}$ partiach i ruchach. Tkwią głęboko w psychice, mentalności i formach myślenia, dyskursu i argumentacji myślicieli posttotalitarnych (Tucker 206)2.

Tucker rozpoznaje dwa rodzaje dziedzictwa ideologii totalitarnej: (1) „atak na język" i (2) „podważanie rozumu”. Z łatwością dostrzega, jak wielu posttotalitarnych autorów służących władzy systemowo posługuje się błędami logicznymi i skorumpowanym językiem, stale sabotując rozum. Co więcej, informacje i teksty takiej natury upowszechniane są w sieciach społecznych i w kontrolowanych mediach elektronicznych, przez co nieuczciwy dyskurs polityczno-społeczny, określany mianem "post-prawdy", staje się dominujący.

Drugi cytat związany jest z instytucjami:

Grzechem pierworodnym odejścia od totalitaryzmu było niepowodzenie w budowaniu instytucji liberalnych. Brak liberalizmu, początkowo niewielki, w połączeniu z brakami w systemie sprawiedliwości, którym nie zaradzono, przerodził się w skorumpowanej demokracji politycznej w większy, populistyczny brak liberalizmu, który nastąpił po krachu ekonomicznym (Tucker 231).

Podstawowym problemem społeczeństw postkomunistycznych było to, że nie udało się im ustanowić zdrowych instytucji liberalnych. Poza tym dużą rolę odgrywały okoliczności w tym sensie, że globalny kryzys finansowy w latach 2007-2008 nieoczekiwanie stworzył ukrytym autokratom możliwość podkopania pozycji pod-

2 Wszystkie tłumaczenia cytatów w tekście pochodzą od tłumaczki artykułu - A.W. 
stawowych instytucji demokratycznych pod pretekstem zwalczania korupcji i zapewniania wzrostu gospodarczego.

Trzeci cytat dotyczy kultury:

Turcja jest $\mathrm{w}$ istocie autorytarna i nieliberalna, a rządzący nią nie polegają na eksporcie surowców; państwo to ma również wspólną historię z Węgrami i innymi krajami Europy Wschodniej. Mimo to mam wątpliwości co do powodzenia ponownej ottomanizacji jako platformy populistycznej. Społeczeństwa posttotalitarne są nowoczesne, miejskie, świeckie, zindustrializowane i w wysokim stopniu piśmienne (Tucker 232).

Seymour Martin Lipset wysuwa argument, że czynnikami kulturowymi „pochodzącymi z różnych historii" trudno jest manipulować, podczas gdy stosunkowo łatwo jest zmienić instytucje polityczne (Lipset 153). Zdaniem Tuckera nie jest prawdopodobne, by „mini-Putinowie” z naszego regionu stworzyli nowoczesne autokracje wzorowane na tureckiej czy rosyjskiej. Chciałbym dodać, że można to wyjaśnić - choć nie w pełni - badając wspólne rozumienie polityki, to znaczy kultury polityczne (zob. dyskusję na temat lokalnej, regionalnej i globalnej kultury w: Sztompka 92).

Czwarty cytat porusza kwestię społeczeństwa obywatelskiego:

Po tym, jak menedżerski neo-totalitaryzm w Europie zniszczył wolność nauki, standardy naukowe i użyteczność akademii sprawowaniu krytycznej kontrolę nad władzą państwa, neo-dysydenci muszą przejąć pałeczkę w mówieniu władzom prawdy. Aby bronić się przed pseudointelektualistami, którzy zniekształcają język i logikę w służbie władz, społeczeństwo potrzebuje pro-demokratycznych intelektualistów, którzy będą pisać o polityce i społeczeństwie jasno, logicznie, krytycznie i uczciwie (Tucker 233).

Bardziej rzeczową konkluzją autora jest stwierdzenie, że totalitaryzm bynajmniej nie umarł, a nawet po części powrócił. Do odparcia i odwrócenia tego trendu Tucker proponuje rozbrajająco proste rozwiązanie: powrót dysydentów i zaniechanie zemsty. Neo-dysydenci mogliby ocalić posttotalitarne społeczeństwa od nienawiści, kłamstw i czystego pragmatyzmu poprzez miłość, prawdę i integralność osobistą. Czas pokaże, czy to rozwiązanie ma jakąś szansę powodzenia...

Przet. Agnieszka Wróblewicz 


\section{BIBLIOGRAFIA}

Ágh, Attila. The Politics of Central Europe. London: SAGE Publications 1998.

Ágh. Attila. "Processes of democratization in the East Central European and Balkan States: Sovereignty-Related Conflicts in the Context of Europeanization". Communist and Post-Communist Studies 32 (1999). S. 269-270.

Fukuyama Francis. "The Primacy of Culture." The Global Resurgence of Democracy. Red. L. Diamond, M. Plattner. Baltimore, MD: The Johns Hopkins University Press, 1996. S. 320-327

Lipset, Seymour Martin. „The Centrality of Political Culture”. The Global Resurgence of Democracy. Red. L. Diamond, M. Plattner. Baltimore, MD: The Johns Hopkins University Press, 1996. S. 150-153.

Sztompka, Piotr. "Civilizational Incompetence: The Trap of Post-Communist Societies". Zeitschrift für Soziologie 22 (1993). S. 85-95.

Tucker, Aviezer. The Legacies of Totalitarianism: A Theoretical Framework. Nowy Jork: Cambridge University Press, 2015. 
